\title{
APLIKASI LAUNDRY BERBASIS JAVA DESKTOP PADA TOKO KUMBAH KLAMBI
}

\author{
Kristina Rifka Anisa1, Tria Hadi Kusmanto², Iim Marfu'ah ${ }^{3}$ \\ 1,2,3 Informatika, Fakultas Teknik dan Ilmu Komputer, Universitas Indraprasta PGRI \\ Jalan Raya Tengah No 80, Kelurahan Gedong, Pasar Rebo, Jakarta Timur \\ 라istinarifka4@gmail.com, 22triahadi226@gmail.com, 33iimmarfuah@yahoo.co.id
}

\begin{abstract}
ABSTRAK
Laundry merupakan suatu kegiatan usaha berbasis jasa pencucian pakaian, selimut, seprei dan bantal, Kumbah Klambi Laundry masih menggunakan cara yang manual dalam mengolah data transaksi laundry seperti mencatatn data pelanggan, mencatat transaksi dan membuat laporan buku besar sehingga proses pengolahan data masih membutuhkan waktu yang cukup lama dan terkadaang sering terjadi masalah di pencatatan dan di rekapan laporan. Untuk menangani masalah tersebut, maka perlu dibangun suatu sistem yang dapat mengolah data laundry secara cepat, tepat dan mengurangi resiko kesalahan. Tujuan penelitian ini adalah untuk menghasilkan sistem informasi pelayanan jasa laundry. Dengan adanya sistem ini diharapkan mampu menangani masalah -masalah yang timbul dalam pengelolaan data laundry.
\end{abstract}

Kata Kunci : Sistem Informasi, Wirausaha, Laundry, Java, MySQL

\section{ABSTRACT}

Laundry is a business activity based on washing clothes, blankets, sheets and pillows, Kumbah Klambi Laundry still uses manual methods in processing laundry transaction data such as recording customer data, recording transactions and making ledger reports so that data processing still requires sufficient time. long and sometimes there are often problems in recording and in report recapitulation. To deal with this problem, it is necessary to build a system that can process laundry data quickly, accurately and reduce the risk of errors. The purpose of this study is to produce a laundry service information system. With this system is expected to be able to handle the problems that arise in the management of laundry data.

Key Word : Information System, Entrepreneur, Laundry, Java, MySQL

\section{PENDAHULUAN}

Pada jaman sekarang ini manusia harus dihadapkan dengan kemajuan dan kecanggihan teknologi dan informasi yang cepat dan mudah. Oleh karena itu perkembangan teknologi tersebut bukan hanya dimanfaatkan oleh diri sendiri saja melainkan harus berguna juga untuk masarakat ramai, Menurut (Kadir, 2014) sistem adalah sekelompok elemen-elemen yang terintegrasi dengan tujuan yang sama untuk mencapai tujuan. Menurut (Kristanto, 2008) Informasi merupakan kumpulan data yang diolah menjadi bentuk lebih berguna dan lebih berarti bagi yang menerimanya. Menurut (Sutarman, 2012) sistem informasi adalah sistem yang dapat didefinisikan dengan mengumpulkan, memproses, menyimpan, menganalisis, menyebarkan informasi untuk tujuan tertentu. Dengan begitu sistem informasi akan cocok digunakan dalam bidang usaha laundry.

Dengan memanfaatkan teknologi informasi sebagai media dalam pengembangan usaha juga dapat mempermudah proses pekerjaan. Banyak dari pengusaha kelas menengah ke atas dalam proses usahanya didukung dengan sistem yang sangat baik sehingga mendapatkan hasil yang efektif dan lebih efisien,

Kebanyakan jasa usaha laundry adalah usaha rumahan, sehingga pengelolaannya dilakukan secara manual dan sederhana, yang artinya setiap ada konsumen datang dibagian penerimaan barang harus membuatkan nota penyerahan dengan manual atau dengan kata lain masih ditulis tangan. Nota tersebut dibagi atas 3 yaitu warna putih untuk pelanggan, warna merah untuk output ada baju laundry, dan warna kuning untuk arsip perusahaan. Hal ini tentunya tidak praktis, karena memakan 
banyak waktu serta membutuhkan keteliatian. Serta untuk mengetahui pendapatan pembelian barang untuk keperluan Toko Kumbah Klambi Laundry juga masih menggunakan pendataan manual sehingga untuk mengetahui jumlah pengeluaran laundry membutuhkan waktu yang relatif lama. Untuk itu diharapkan ingin dibuat sistem informasi agar pencatatan pengeluaran dan pendapatan laundry dapat berjalan cepat, efektif dan efisien.

Dalam melakukan penelitian ini, peneliti menggunakan beberapa referensi dari penelitian lain sebagai acuan untuk menghasilkan penelitian yang baik, diantaranya penelitian oleh (Dirajat, 2010) dengan judul Perancangan Sistem Aplikasi Administrasi Pada Laundry Orange Sleman Yogyakarta. Penelitian ini bertujuan untuk dasar merancang dan membuat program aplikasi dan proses pengolahan data administrasi. Penelitian oleh (Kurniawan, 2010) dengan judul Analisis Dan Perancangan Sistem Informasi Jasa Laundry Dengan Menggunakan Microsoft Visual Basic 6.0. Penelitian ini menghasilkan rancangan basis data yang digunakan untuk referensi dalam pembuatan program aplikasi.

\section{METODE PENELITIAN}

Metode penelitian yang peneliti gunakan adalah metode grounded research, (Greenberg, 2010) menjelaskan grounded theory or grounded methodology is most often derived from data sources of aqualitative. Penelitian dilakukan di Toko Kumbah Klambi Laundry yang beralamat di Jl. Swadaya 1 no 64, RT 11 RW 10, Pejaten Timur, Pasar Minggu, Jakarta Selatan.
Flowchart penelitian Penulis :

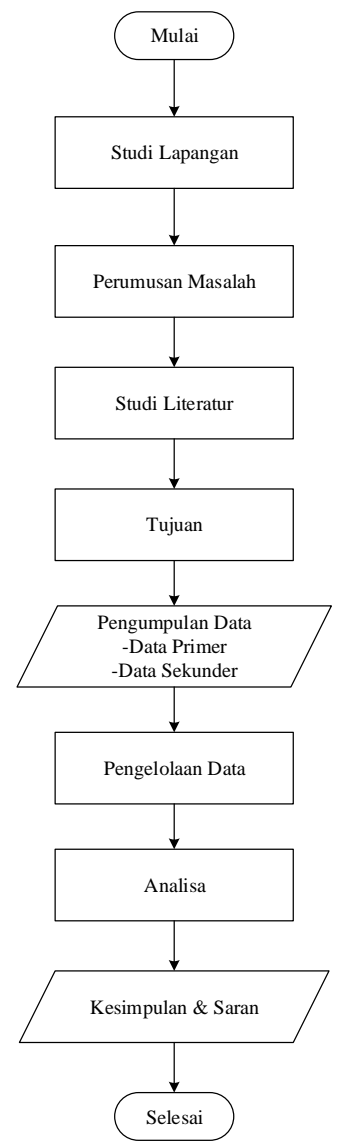

Gambar 1. Flowchart Proses Penelitian

\section{Metode Pengumpulan Data}

1. Wawancara

Dalam penelitian jurnalistik, wawancara adalah suatu percakapan terpimpin dan tercatat atau suatu percakapan secara tatap muka dimana seseorang mendapat informasi dari orang lain.

2. Observasi

Peneliti melakukan pengamatan secara langsung kegiatan transaksi dari mulai pencatatan pelanggan sampai transaksi di Kumbah Klambi Laundry untuk mempelajari proses dan melengkapai data yang diperlukan.

3. Dokumentasi

Peneliti melakukan pengumpulan data dengan cara melihat dan mencatat data yang ada pada arsip Toko Kumbah Klambi Laundry.

HASIL DAN PEMBAHASAN

Pada perkembangan teknik pemrograman berorientasi objek, muncul sebuah standarisasi bahasa pemodelan untuk pembangunan perangkat lunak yang dibangun 
dengan menggunakan teknik pemrograman berorientasi objek yaitu Unified Modelling Language (UML). UML merupakan bahasa visual yang menjadi standar untuk menspesifikasikan, menggambarkan, membangun, dan dokumentasi dari sistem perangkat lunak (Ir. Yuni Sugiarti, 2013), sehingga pemodelan ini cocok digunakan untuk merancang dan membangun penelitian peneliti.Menurut (C.R., 2020) Java Desktop adalah aplikasi yang dibuat dengan bahasa pemrograman Java untuk komputer desktop. Artinya aplikasi ini hanya dapat dijalankan pada ruang lingkup terbatas. Berbeda dengan aplikasi web yang dapat diakses lewat browser dimana saja. Menurut (Pratama, 2010) MySQL yaitu suatu sistem managemen basis data relasional yang mampu bekerja dengan cepat, kokoh dan mudah digunakan. Sehingga jadi referensi peneliti untuk melakukan manajemen basis data.

\section{Use Case Diagram}

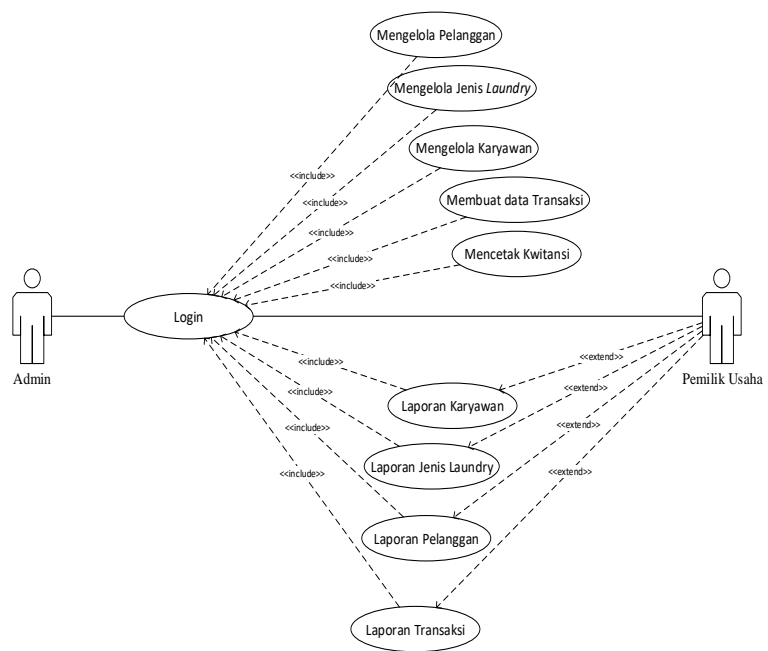

Gambar 2. Use Case Sistem yang diusulkan

\section{Activity Diagram Login}

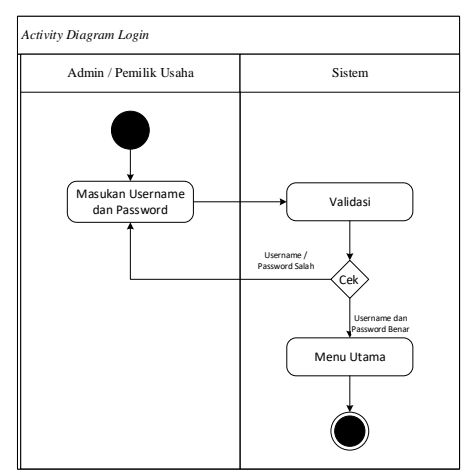

Gambar 3. Activity Diagram Login
Adalah aktivitas yang dilakukan sebelum bisa masuk ke menu utama, berisi username dan password akses system.

\section{Activity Diagram Transaksi}

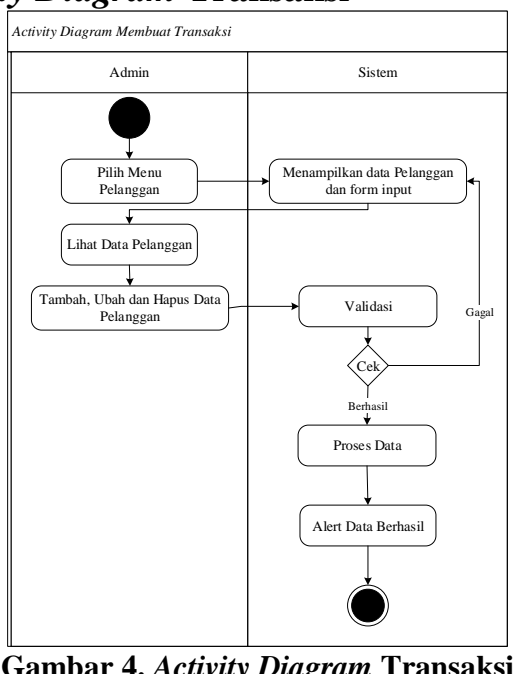

Adalah aktivitas dimana terjadinya transaksi antara pelanggan dan admin laundry, untuk pencatatan transaksi

\section{Activity Diagram Laporan Transaksi}

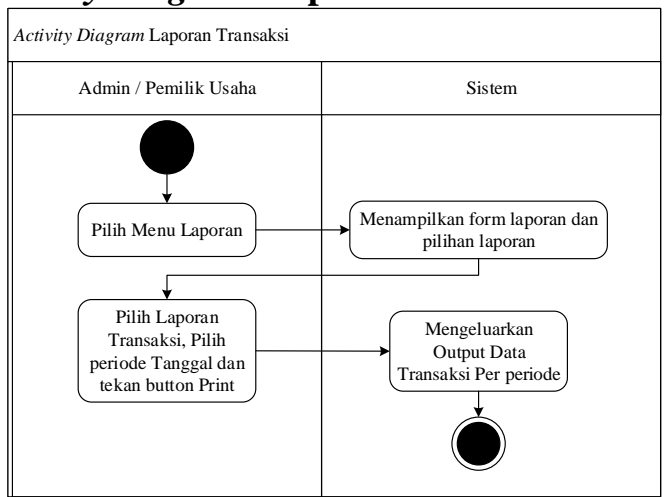

Gambar 5. Activity Diagram Laporan Transaksi

Adalah aktivitas dimana admin dapat melihat serta mencetak laporan transaksi yang terjadi

\section{Sequence Diagram Transaksi}

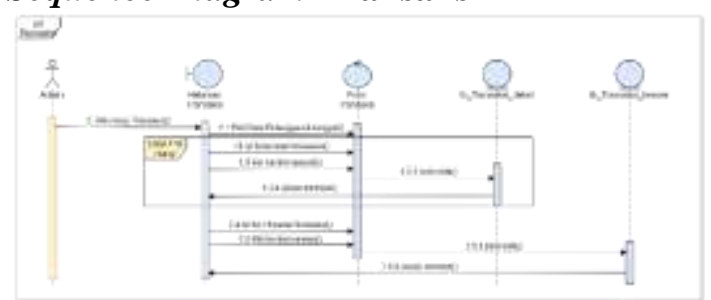

Gambar 6. Sequence Diagram Transaksi

Adalah proses sequence pada saat admin melakukan pencatatan transaksi di sistem. 


\section{Class Diagram Laundry}

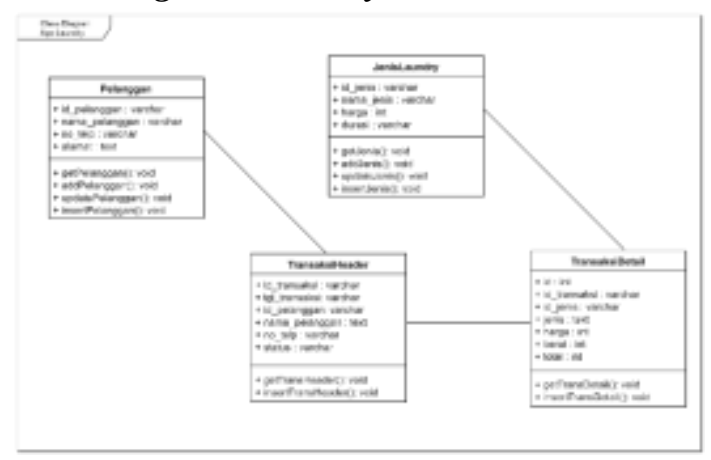

Gambar 7. Class Diagram Laundry

Adalah cikal bakal basis data yang digunakan untuk perancangan program/ sistem.

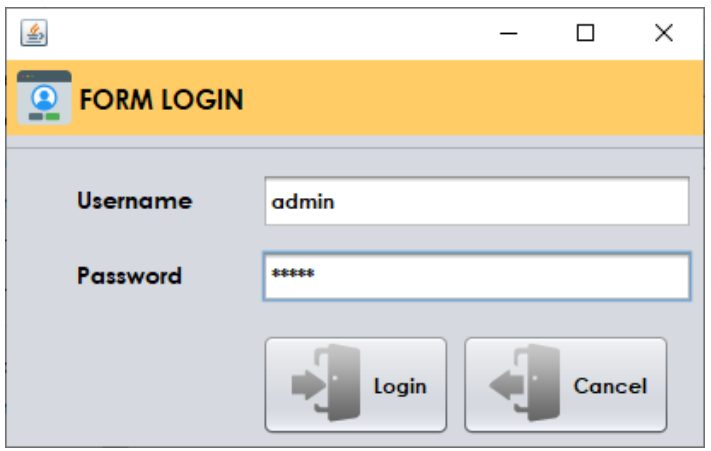

Gambar 8. Form Login

Adalah form yang akan muncul sebelum admin dapat mengakses menu utama, berisi username dan password untuk akses, jika benar maka akan lanjut ke menu selanjutnya.

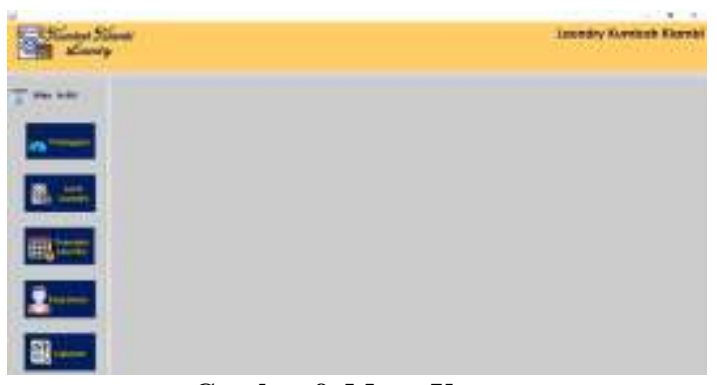

Gambar 9. Menu Utama

Adalah tampilan utama ketika admin berhasil login ke sistem, berisi dari beberapa menu master, transaksi dan report.

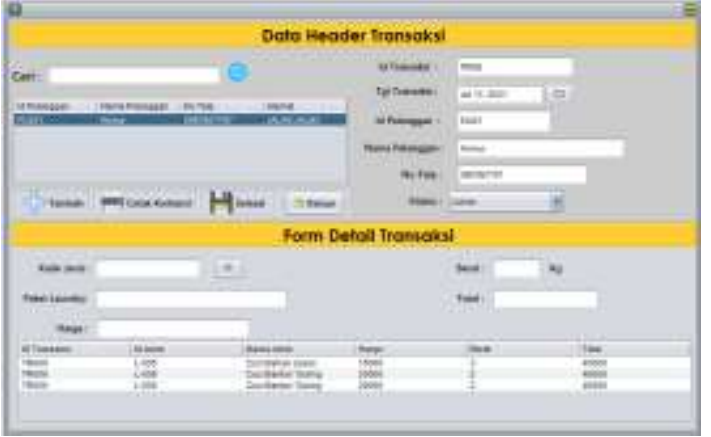

Gambar 10 Form Transaksi

Adalah tampilan ketika admin melakukan pencatatan transaksi di system, denga nisi header transaksi dan detail transaksi serta ada fasilitas untuk cetak nota/ kwitansi

\section{SIMPULAN DAN SARAN}

Peluang usaha laundry dapat dikategorikan sebagai usaha dengan cakupan luas, karena dilihat dari aspek kebutuhan masyarakat dan daya kepercayaan masyarakat terhadap suatu usaha, serta adanya kualitas pewangi, mesin cuci, air, harga yang bersaing dan pelayanan yang terbaik sehingga membuat pelanggan tetap menggunakan jasa laundry ini, adanya dukungan dari tempat usaha yang dikelilingi masyarakat ramai dan tentunya ditambah dengan sistem membuat usaha semakin efisien dan efektif. Meskipun jenis usaha ini membutuhkan modal yang tidak sedikit, namun seiring berjalan waktu tentunya akan menjadikan usaha yang menjanjikan.

Dalam menjalankan bisnis laundry yang harus diperhatikan yaitu tempat usaha yang strategis, misalnya di Kawasan padat penduduk atau Kawasan penduduk yang mayoritas bekerja, sehingga transaksi yang dilakukan lumayan banyak. Perlunya pelayanan yang memuaskan kepada pelanggan agar meningkatkan kepercayaan pelanggan, serta kualitas mesin cuci dan pewangi ditambah dengan adanya sistem informasi agar mempermudah dalam transaksi.

\section{UCAPAN TERIMAKASIH}

Ucapan Terima Kasih disajikan secara singkat sebagai bentuk apresiasi terhadap pihak-pihak meliputi Lembaga pemberi dana, mitra kerja, dan perorangan yang berkontribusi dalam penelitian ini. 


\section{DAFTAR PUSTAKA}

C.R., R. (2020, January 2). marisharingilmu. Retrieved from MARI BERBAGI: https://marisharingilmu.wordpress.co $\mathrm{m} / \mathrm{tag} /$ apa-itu-java-desktop/

Dirajat, I. Y. (2010). Perancangan Sistem Aplikasi Administrasi Pada Laundry Orange Sleman Yogyakarta. Yogyakarta: Sekolah Tinggi Manajemen Informatika dan Komputer.

Greenberg, P. (2010). CRM at the Speed of Light, Fourth Edition: Social CRM 2.0 Strategies, Tools, and Techniques for. McGraw-Hill Education.

Ir. Yuni Sugiarti, M. K. (2013). Analisis \& Perancangan UML (Unified Modeling Language) Generated VB.6. Jakarta: Graha Ilmu.

Jogiyanto, H. M. (n.d.). Analisa \& Desain Sistem Informasi Pendekatan Terstruktur Teori dan Praktek Aplikasi Bisnis. Yogyakarta: Andi.

Kadir, A. (2014). Pengertian Sistem Informasi, Pengenalan Sistem Informasi Edisi Revisi. Yogyakarta: Andi.

Kristanto, A. (2008). Perancangan Sistem Informasi dan Aplikasi. Bandung: Informatika.

Kurniawan, H. (2010). Analisis Dan Perancangan Sistem Informasi Jasa Laundry Dengan Menggunakan Microsoft Visual Basic 6.0. Depok: Universitas Gunadharma Prodi Teknik Informatika.

Lajamudin, A. (2005). Analisis dan Desain Sistem Informasi. Yogyakarta: Graha Ilmu.

Pratama, A. N. (2010). Cara Mudah Membangun Aplikasi PHP. Jakarta Selatan: Transmedia.

Sutarman. (2012). Pengantar Teknologi Informasi. Bumi Aksara. 